\title{
Comentário VII
}

\author{
Maria Fernanda B. Bicalho \\ Departamento de História, Instituto de Ciências \\ Humanas e Filosofia/Universidade Federal \\ Fluminense
}

Uma das atitudes com que invariavelmente nos deparamos neste ofício de historiadores, é uma certa perplexidade dos "leigos" - ou seja, daquelas pessoas que não trabalham com a história - que nos olham um pouco admiradas, um pouco hesitantes entre a curiosidade e a estranheza, tentando entender o que leva alguém a se dedicar apaixonada e profissionalmente a algo tão "distante" - ainda mais se pensarmos na praticidade e no imediatismo que regem os dias de hoje, e que informam igualmente a "vocação" profissional de muitos.

Que estranha fixação moveria os historiadores, pessoas "descontextualizadas" no tempo, que vivem "antenadas" no passado por meio de um ofício que ainda por cima não thes rende muito dinheiro? Seriam seres de um outro mundo? Incrédulos diante desta hipótese, e na tentativa de transformar sua perplexidade em argumento razoável, alguns "leigos" justificam ser importante entender a história, pois a compreensão do passado possibilita uma melhor percepção, do presente com vistas à construção de um futuro mais "coerente" e humano. É portanto corrente a idéia - não apenas entre os "leigos", mas certamente no seio dos historiadores de profissão - de que o estudo da história e a sua reconstituição historiográfica são instrumentos de intervenção no presente e no próprio devir dos homens e das sociedades. Compreender a história nos conferiria meios para sermos dela agentes, não apenas no "papel" - ou em livros - mas na vida real.

Ao receber a "encomenda" e a enorme responsabilidade de realizar - e redigir - um comentário crítico acerca do texto de Ronaldo Vainfas, História 
da vida privada: dilemas, paradigmas, escalas, enquanto o lia, ia tomando consciência da difícil tarefa da qual havia sido incumbida e a qual, com muito prazer, havia aceito. A dificuldade que senti diz respeito ao fato de se tratar de um texto denso, consistente e - ele próprio - crítico, colocando dessa forma o seu debatedor numa situação bastante árdua, pela grande capacidade do autor em dar conta dos múltiplos meandros de uma discusão que envolve as influências, aproximações e relações teórico-metodológicas entre o fazer uma História da Vida Privada e as recentes - e algumas delas polêmicas - tendências da historiografia francesa e internacional. Em segundo lugar, confesso-me seduzida pela argúcia com que Vainfas argumenta, hesita, afirma e desvenda as incongruências de uma história que se quer da vida privada, sentindo-me muito mais inclinada a concordar com tudo, do que a contrapor ou sugerir novos caminhos.

No entanto, levantarei algumas questões acerca daquilo que a meu ver é mais afirmativo em seu texto, ou seja, acerca das hesitações, dos impasses, dos dilemas, e da incipiência deste novo campo de investigação. Segundo Vainfas, o "território da vida privada", ou de uma privacidade ainda carente de conceituação, se constrói ou é perpassado por uma "fragilidade desconcertante". Tal fragilidade traduzir-se-ia na própria definição - ou indefinição - teórica do objeto, perceptível nos estudos dos historiadores que se debruçaram sobre esse domínio do social; prevalecendo, sobretudo, uma "tendência negativa", ou seja, "a preocupação em dizer 'o que a vida privada não é" : opondo-se ao público, distinguindo-se da vida cotidiana, recusando-se a ser a história da preeminência do individualismo.

Vainfas cita o "Prefácio" introdutório à coleção citada, escrito por Georges Duby, no qual o historiador francês se pergunta sobre a licitude da vida privada como objeto ou como esfera da vida social necessariamente presente nas diferentes sociedades e em todos os períodos históricos. Na "Advertência" ao segundo volume, Duby voltaria a se colocar a questão da legitimidade - e não apenas da pertinência - de se falar da vida privada na Idade Média: "transpor a um passado tão distante uma noção, a de privacy, que, como sabemos, formou-se no decorrer do século XIX no seio da sociedade anglo-saxã, então na vanguarda da elaboração de uma cultura 'burguesa'?" Embora responda de forma afirmativa, insiste em que "se trata de uma exploração pioneira, muito tateante, incerta", por considerar o conceito de vida privada às vezes "anacrônico". Outro perigo de anacronismo seria associá-lo ao individualismo tout court. Assim, opondo-se ao público e negando uma relação direta com o surgimento do individualismo - ou da intimidade no sentido moderno - o novo domínio historiográfico aberto pela coleção francesa, já tendo encontrado seus autores, anda ainda à busca de uma "identidade" afirmativa e de uma conceituação mais precisa.

De todas estas incongruências, já de antemão apontadas pelos organizadores da coleção francesa - e ressaltadas por Vainfas - percebo uma que considero não constituir propriamente uma oposição, sendo a meu ver, a mais reveladora da possibilidade legítima e sem hesitações insuperáveis de se fazer uma História da Vida Privada.

No momento em que Vainfas faz a classificação dos períodos e dos temas abordados nos cinco volumes da coleção, demonstra a predominância do 
recorte temático que insiste na recorrência de abordagens da família numa perspectiva próxima às relações domésticas marcadas pelo individualismo, pela valorização das intimidades, pela discussão da sexualidade, pela emergência dos sentimentos pessoais, contradizendo aquilo que Duby prevenira na sua "Advertência". Se por um lado isso não causa espanto, na medida em que, segundo Vainfas, tais temas são privilegiados no volume 3 ("Do Renascimento ao Século das Luzes", que apesar de abarcar um longo período onde conceitos pedidos "de empréstimo" à antropologia - como os de aliança, parentesco e inhagem - poderiam ser predominantes, trata mais especificamente "da gênese da vida privada em termos de familiaridade"); no volume 4 ("Da Revolução à Grande Guerra", este sim, compreendendo o século XIX que, segundo Duby, viu emergir o sentimento de privacy, e que aborda prioritariamente a "cristalização do modelo burguês de família"), e no volume 5 ("Da Primeira Guerra Mundial aos nossos dias", com "ênfase nas mudanças éticas e comportamentais das décadas de 1960 e 1970"). E a conclusão a que chega Vainfas, baseando-se nesta amostragem, aponta para mais esta incongruência entre as temáticas privilegiadas nos artigos da coleção e a advertência introdutória de seus organizadores. Em suas palavras, "elegendo a História da Vida. Privada na Europa Ocidental como objeto de estudo, a série organizada por Áriès e Duby teria mesmo que se concentrar, em primeiro lugar, no processo de construção da privacidade e do individualismo". Nesse sentido, o conceito de vida privada mais explicitamente ligado à intimidade, à domesticidade e à familiaridade, nos moldes em que elas foram erigidas enquanto valores e vivências a partir do século XIX, não seria extrapolável a outros períodos, nem a outras sociedades.

Seria esta uma contradição que inviabilizaria o fazer historiográfico deste domínio da vida social, ou mesmo a tentativa de historicizar a noção ou o conceito de vida privada? Acredito que não, na medida em que os próprios historiadores que a ela se dedicaram nos dão a "chave" do deslocamento e da remissão desta aparente contradição ou do "pecado original" de uma obra que se quer propulsora de novas pesquisas e estudos sobre o assunto. Refiro-me à sugestão de Duby, em seus escritos introdutórios, de que se amplie e se diversifique o enfoque do "território" do privado, na consideração de que o alcance da vida privada pode ser bem maior do que se imagina. E assim reitera a crença na possibilidade de que ela venha a se tornar uma problemática universal da história e da historiografria, ao afirmar reconhecer no vocabulário de épocas passadas "o contraste, claramente detectado pelo senso comum, entre o privado e o público".

Seria então essa oposição - talvez a mais controvertida entre tantas outras - o instrumento privilegiado, senão para conceituar, ao menos para delimitar o "espaço" da vida privada? Sim e não. Sim, pelo que afirma Duby acerca da percepção de um contraste entre o público e o privado nas diferentes sociedades e épocas. Não, pelo que ele - e muitos outros autores da obra coletiva - de fato enunciam e fazem, sobretudo aqueles que se reportaram a tempos remotos (volumes 1 e 2), demonstrando, como afirma Vainfas, a "'confusão' entre público e privado nas várias esferas da vida social, quando não escolhem este tema como objeto do ensaio, a exemplo do próprio Georges Duby no artigo inaugural do segundo volume: 'Poder privado, poder público'". 
Ainda em relação à classificação dos temas predominantes nos artigos que compõem a obra coletiva, Vainfas se surpreende com o relativamente modesto índice de artigos dedicados à "casa" e aos espaços domésticos, territórios por excelência de desenvolvimento e experimentação do sentimento de "privacidade" do indivíduo moderno e que, a seu ver, constitui "um assunto essencial para a abordagem da vida privada". Verifica, ao contrário, que um número expressivo dos mesmos artigos é dedicado ao problema das relações entre o público e o privado: "textos quase sempre preocupados em dimensionar a gênese ou os modelos da privacidade no Ocidente em termos macro-históricos, ora examinando a confusão entre o público e o privado em épocas pretéritas, ora vasculhando a ilusão de privacidade no mundo contemporâneo." E conclui serem estes estudos, de fato, os que "propõem othares inovadores sobre as relações privado/público em várias épocas, inclusive em tournants historicamente expressivos, dando mostra significativa das potencialidades de uma História da Vida Privada como temática global de investigação".

Concordo inteiramente com esta afirmação. Aliás, a imprecisão dos limites e das fronteiras entre os domínios público e privado que marcou algumas sociedades do passado, pode ser percebida, respeitando as profundas diferenças, na atualidade, momento de profunda afirmação e de pleno desenvolvimento do individualismo, como aliás argumentam, embora sob perspectivas opostas, Georges Duby e Richard Sennett, como nos demonstram as considerações finais de Vainfas.

Mas antes de comentá-las, gostaria de dar um exemplo - desta feita "extra-europeu" - a partir das hipóteses e conclusões do meu trabalho de mestrado sobre a imprensa feminina - jornais escritos por mulheres e a elas dirigidos - no Rio de Janeiro na segunda metade do século XIX (Bicalho 1988). Nele procuro discutir a manifestação do individualismo na sociedade - patriarcal e escravista - brasileira, a partir das reflexões de autores como Lovis Dumont (1985) e Georg Simmel (1971 e 1989), privilegiando ainda, na pista deste último, a importância da noção de subjetividade na construção do indivíduo enquanto categoria histórica e sociológica dos tempos atuais. Tento mostrar que embora o espaço privado - da casa, da família, da intimidade doméstica - seja um dos locus privilegiados para afirmação da subjetividade individual - e no caso específico que me interessava, para a construção de uma nova identidade feminina - esse espaço, não obstante, estava longe de ser o único apropriado para tal fim. Ao contrário, a imprensa - veículo por excelência de circulação no espaço público e de formação de uma opinião pública - foi o instrumento eleito por algumas mulheres para a expressão da sua subjetividade e para a abertura de uma brecha que thes permitisse se afirmarem no domínio público do trabalho e da política.

Em outras palavras, através da análise do discurso dos jornais femininos pretendi discutir a identidade da mulher retratada por este tipo de imprensa, a mulher urbana, educada, "burguesa", que aos poucos descobria o mundo à sua volta, com o qual começava a interagir, querendo conquistar um espaço seu. A mulher vista "nos seus próprios termos", percebida à luz do discurso de sua subjetividade, tornado público através da imprensa. De fato estes jonais tinham muito de diários, memórias, escritos íntimos, expressão do individualismo 
e do romantismo então emergentes, gênero literário tão vorazmente consumido pelas moças e senhoras daquela época, que mal haviam saido do confinamento das alcovas, cujo isolamento thes impunha uma incomunicabilidade forçada com o mundo exterior. Nesse sentido, os artigos que compunham os mesmos jornais tinham muito de registro da intimidade doméstica, privada, familiar. Mas no ato de sua publicação - ou "publicização" - transparecia a busca consciente de um - ou uma - interlocutora, e a tentativa de construção de uma identidade social.

Esse tipo de imprensa pode ser comparado aos hebdomadários que, segundo Habermas, invadiram a Europa após 1750, dirigidos a um público "que apaixonadamente tematiza a si mesmo", e que "busca no raciocínio público das pessoas privadas" entendimento mútuo e esclarecimento de "experiências que fluem de fontes de uma subjetividade específica", nascida no lar e na esfera familiar (Habermas 1984: 60). Exemplo disso é a carta de uma assinante do Jornal das Senhoras, dirigida à sua redatora, e transcrita em um de seus primeiros números, a 8 de fevereiro de 1852:

\begin{abstract}
"Em dias deste mês, estava eu passando pelos olhos o Jornal do Comércio, sem deparar nele coisa que me interessasse mais intimaménte, quando vi de repente um anúncio - 0 Jornal das Senhoras. Corri à sala de meu pai e pedithe que o mandasse buscarr.

Apenas chegou, fui devorando-o, e logo no principio acho um convite para todas as que quiserem concorrer com seu cabedal, e ocupar um lugarzinho nas páginas do jornal. Foi o mesmo que se estivesse com muita sede e calor, e a senhora me oferecesse um sorvete. (...)

A senhora veio-nos abrir um campo de atividade, em que podemos exercitar as nossas forças, e sair do nosso estado de vegetação. Como the agradecemos?

Demais, que prazer o de escrever alguma coisa em letra redonda; saber que as outras lêem nossos pensamentos. Tanto que eu desejava isto, agora a senhora me oferece uma oportunidade."
\end{abstract}

Assim, a imprensa feminina abriu, na segunda metade do século XIX, um espaço de "sociabilidade" para mulheres que haviam vivido até então isoladas no recolhimento de seus lares, proporcionando às suas leitoras um meio de comunicação eminentemente público.

Mas não só. A educação feminina, tema privilegiado por aqueles jornais, era defendida como suporte indispensável à "emancipação da muther". Essa reivindicação vinha imbuída de uma tentativa de sua promoção no interior do espaço doméstico ao enfatizar a grande influência que a mãe educada teria na formação dos filhos, na moralização da família e na conseqüente "regeneração" da sociedade. Através da valorização do papel materno e do reconhecimento de sua intervenção moralizadora numa esfera mais ampla do social, a imprensa feminina reivindicava para o "belo sexo" a conquista de um espaço até então exclusivamente identificado com o sexo masculino: a esfera do público, domínio do trabalho e da política. Ora privilegiando a representação tradicional - e de conteúdo relacional - da mulher enquanto esposa e mãe dedicada, ora defendendo a afirmação de sua individualidade através da construção de uma identidade profissional e política, esse discurso era sem dúvida permeado por ambigüidades e tensões. Ambigüidades e tensões próprias de um "feminismo" que se afirmava naquela época. 
Mas não quero me delongar aqui sobre $\circ$ meu próprio trabalho, apenas demonstrar - se é que me fiz clara utilizando-o como exemplo - que talvez uma boa "saída" para a análise de temas ligados à vida privada seja encarar $\circ$ público e o privado não como duas facetas distintas de uma oposição, mas como esferas, não diria "confusas", mas interpenetráveis, auto-constituintes. Estes dois domínios a princípio opostos, formam muitas vezes, a meu ver, um grande território, permeado por ambiguidades, algumas indistinções e muitas inter-relações, cujo desvendamento em épocas e sociedades distintas permitiria não apenas a realização de uma História da Vida Privada, mas ainda sua perfeita legitimidade na determinação de constantes e na explicitação das diferenças. Aliás, como diria Paul Veyne, somente jogando com as variáveis se pode recriar, a partir de uma constante, a diversidade das modificações históricas (Veyne 1983: 151.

Mas voltando à estranheza causada nos "leigos" pelo ofício do historiador, e de certo modo explicada pela relação entre a busca do conhecimento do passado interessada na compreensão do presente e visando a ação no futuro; invertendo os termos desta equação, me remeto mais uma vez à Veyne, para quem "a história existe apenas em relação, às questões que nós the formulamos" (1983: 6). Ou seja, se o passado informa o presente, inversamente, as questões para as quais procuramos respostas em tempos e sociedades remotas são, por sua vez, questões atuais, produto de nossa vivência cotidiana e intelectual. Assim, o atual interesse pela vida privada enquanto questão historiográfica - "presumidamente nova" - se deve em parte ao fato de ela constituir uma problemática da experiência do homem atual diante da extrema indefinição, também hoje em dia e nas nossas sociedades, das fronteiras entre o público e o privado.

Como afirma Vainfas a partir da citação de Duby transcrita no final de seu ensaio, o estudo da História da Vida Privada vem atender a uma expectativa do mundo contemporâneo na virada do milênio. Para o historiador francês, o homem do final do século XX se defronta com um estrangulamento de valores até então primordiais, massacrado por um estonteante progresso técnico que desqualifica e anula as individualidades particulares, conduzindo em última instância ao esfacelamento das fronteiras entre público e privado - duas categorias não apenas historiográficas, mas norteadoras de nosso modo de ver e de nos inserirmos no mundo. Mesmo em direção totalmente oposta, Sennett tematiza o mesmo sentimento de angústia do mundo contemporâneo diante de um total desmantelamento ou de uma profunda erosão, não da "essência da pessoa", como queria Duby, mas do espaço público, submetido ao império do individualismo e às tiranias do "self".

Permitindo-me uma brincadeira com as oposições binárias de Lévi-Strauss, ambos, Sennett e Duby, referem-se "estruturalmente" a uma mesma coisa, se considerarmos o seu aspecto formal. Falam do esfacelamento das oposições que até então dirigiram nossas vidas e nossa maneira de pensar, e que, se por um lado produz essa angústia, por outro, leva-nos, historiadores e sociólogos, a tematizá-la, a erigíla como objeto de investigação.

Mas isso não quer dizer que este objeto apareça em suas respectivas teorizações esfacelado, ou que o seu recorte e problematização conduzam a um 
esfacelamento da teoria e dos métodos da história. E neste ponto discordo de que a vida privada, como os demais temas eleitos enquanto campo de investigação de tendências historiográficas mais recentes levem a uma pulverização das totalidades históricas, à confusão epistemológica entre sujeito e objeto, ou à renúncia à explicação. Concordo portanto com Vainfas quando defende que a "invenção" da vida privada enquanto objeto da história, embora possa adotar uma escala microscópica de observação, ilumina aspectos de uma "escala macro-histórica".

Desta forma, mais do que a fragmentação ou a redução da história em migalhas, acredito que a investida da historiografia - seja ela "Nova" ou "Micro" - no campo de investigação aberto pelo interesse pela vida privada, ao escolher uma "escala". particular de observação, ao colocar em relação diferentes niveis da realidade e ao confrontar a perenidade das representações mentais com a diversidade e originalidade das pequenas "aldeias", é perfeitamente capaz de forjar não apenas uma identidade conceitual, mas ainda - e sobretudo - uma démarche totalizante. Afinal, citando Paul Veyne (1983: 30; 40), "estamos errados quando opomos a apreensão das individualidades, em toda a sua riqueza, à conceituação". E o que é a tarefa da história senão "conceituar, a fim de delimitar a originalidade das coisas"? 